\title{
AÇÃO COLETIVA NA FEDERAÇÃO DAS INDÚSTRIAS DO ESTADO DO PARANÁ (2003-2011)
}

José Augusto Hartmann ${ }^{2}$

\begin{abstract}
Resumo
Objetiva-se apresentar análise sobre valores, preferências e, sobretudo, ação do empresariado industrial paranaense acerca da política e democracia. Espera-se apontar para formas de organização e ação política, além de compreensão do comportamento, do empresariado industrial paranaense. Compreende-se que as formas com que o empresariado pensa a política podem indicar suas preferências e formas de ação, assim como influência no processo decisório. Delimita-se a atuação empresarial por meio de entidades de representação política, no caso a Federação paranaense, entendidas como grupo de interesse. A metodologia empregada para este artigo será a análise de três formas de ação divulgadas pela entidade representativa dos industriários paranaenses, a Federação das Indústrias do Estado do Paraná (FIEP), a saber, a (i) Rede de Participação Política, o (ii) Movimento A Sombra do Imposto e (iii) a revista Observatório da Indústria.
\end{abstract}

Palavras-chave: Empresariado Industrial, Ação Coletiva, FIEP.

\begin{abstract}
The objective is to analyze values, preferences and action of Paraná industrial business about politics and democracy. Expected to provide, forms of political organization and action, as well as understanding the behavior of the industrial business of Paraná. It is understood that the ways in which the business thinks the policy may indicate your preferences and forms of collective actions, as well as influence in decision-making. The businessmen organized activities are examined by political representation entities, therefore, has as a research subject a group of interest, and political pressure. The methodology used for this article is the analysis of three forms of action disclosed by the entity representing the Paraná industrialists, the Federation of Industries of the State of Paraná (FIEP), namely (i) Rede de Participação Política, the (ii) Movimento A Sombra do Imposto and (iii) Revista Observatório da Indústria.
\end{abstract}

Keywords: Industrial Entrepreneurship, Collective Action, FIEP.

\section{Resumen}

El objetivo de este artículo es presentar análisis de los valores, preferencias y, sobre todo, la acción política de los empresarios industriales del Paraná. Se desea apuntar para formas de organización y acción, así como contribuir para la comprensión del comportamiento de la comunidad industrial del Paraná. Se entiende que las formas como los industriales piensan la política, puede indicar sus preferencias, sus formas de acción e influencia en el proceso de toma de decisiones. Se delimita las actividades políticas empresariales a través de la representación política de las federaciones industriales, en este caso, de la Federação das Indústrias do Estado do Paraná (FIEP), entendida como un grupo de interés. La metodología utilizada en este artículo es el análisis de tres formas de acción desarrolladas por el sindicato de los industriales de Paraná, a saber, (i) la Rede de Participação Política, el (ii) Movimento A Sombra do Imposto y (iii) la revista Observatório da Indústria.

Palabras-clave: Empresariado Industrial, Accíon Colectiva, FIEP.

\footnotetext{
${ }^{1}$ DOI deste artigo: http://dx.doi.org/10.5380/recp.v5i2.37497

${ }^{2}$ Mestrando em ciência política pela Univerdidade Federal do Paraná.
} 


\section{INTRODUÇÃO}

Almond e Verba (1989, p.12) afirmaram haver uma "cultura política" que acaba por referenciar e orientar as atitudes em relação ao sistema político. ${ }^{3}$ Nesse sentido, o comportamento dos atores é visto sob a influência de valores, e tido como elemento fundamental para compreensão da política. Os grupos, entendidos como unidades com características e interesses comuns, compartilham isso entre si e, consequentemente, passam a organizar-se para uma ação coletiva. (TRUMAN, 1951, p.37) Também nesse sentido, Easton, identificava a participação relacionada a uma "[...] sensação de estar do mesmo lado, de ter ideais e pressuposições comuns, de haver respeito mútuo pelos interesses particulares, procurando ajuda e apoio recíprocos, ou de aceitar uma liderança comum.” (EASTON, 1968, p.23) Dahl apontava para crenças comuns, gerando preferências e motivando ações, como pode ser verificado na própria crença no sistema democrático como fundamental para seu funcionamento, ainda que o central em sua análise seja a quantidade e capacidade dos atores em utilizar recursos escassos para fazer valer suas preferências. (DAHL, 1989, p.305) Deste modo, considera-se a formação de grupos de interesse, dispostos a pressionar por suas preferências, impedindo o controle das decisões por uma única elite. ${ }^{4}$

Contudo, a defesa de uma tendência à ação coletiva por um grupo sofreu incisivos questionamentos de Mancur Olson (2011). O autor afirma que "[...] os indivíduos racionais e centrados nos próprios interesses não agirão para promover seus interesses comuns ou grupais." (OLSON, 2011, p. 14) Salvo em grupos pequenos, onde o custo da ação necessita ser tomado por todos os integrantes do grupo, confundindo-se com os custos individuais, em grupos maiores a ação coletiva depende de “[...] coerção ou alguma indução externa que leve os membros do grande grupo a agirem em prol de seus interesses comuns." (OLSON, 2011, p.57). Disso decorreu, no Brasil, a tese de que o empresariado seria incapaz de organizar-se em torno de uma pauta comum, tornando-se dependente do Estado. (MANCUSO, 2007, p.153) Neste seguinte artigo, apresenta-se uma abordagem desse problema à luz do trabalho de Wagner Mancuso (2007), que lança mão de uma metodologia pluralista para examinar a ação política da Confederação Nacional da Indústria (CNI).

\footnotetext{
3 "The term 'political culture' thus refers to the specifically political orientations - attitudes toward the political system and its various parts, and attitudes toward the role of the self in the system. We speak of a political culture just as we can speak of an economic culture or a religious culture. It is a set of orientations toward a special set of social objects and processes." (ALMOND; VERBA, 1989, p.12)

${ }^{4}$ Ver crítica de Dahl sobre o modelo de elite dirigente de Wright Mills: DAHL, Robert. Uma crítica do modelo de elite dirigente. In: Sociologia Política II, Rio de Janeiro: Zahar Editores, 1970. pp. 90-100.
} 
Cabe destacar desde já que, para o que esta pesquisa se propõe, há necessidade de impor cautela ao considerar uma relação entre valores, preferências e ações, reconhecendo constrangimentos coercitivos e corporativos na organização empresarial no Brasil, podendo-se, contudo, concluir por ela, desde que, se tome o entendimento de que os temas não apresentam-se numa relação de causa e efeito, mas como articulados (COSTA; ENGLER, 2008, p.488).

Portanto, este paper objetiva analisar dados referentes a ação e, a partir disso, expor informações referentes aos valores e preferências de parte da elite empresarial paranaense acerca da política e, mais especificamente, da sua concepção de democracia. $\mathrm{O}$ que se está tomando como objeto de análise é uma entidade de representação industrial: a Federação das Indústrias do Estado do Paraná (FIEP). Propõe-se apresentar três formas de ação política da parte do empresariado industrial representado por essa entidade. Conjectura-se que a ação política da federação dos sindicatos patronais acaba por evidenciar os valores dessa elite empresarial na medida em que objetiva ir de encontro aos seus interesses e preferências, expostos nas apresentações dos projetos analisados, ainda que os resultados possam ser negativos à entidade/empresários.

Destaca-se que a escolha pela Federação das Indústrias do Paraná deve-se ao caráter inovador e proativo dessa federação patronal. Sobre o protagonismo dos empresários industriais em relação à política, Bresser-Pereira e Eli Diniz apontaram para a crescente preocupação com a macroeconomia e atuação política do empresariado nos anos 2000, destacando entidades estaduais, como a FIEP (BRESSER-PEREIRA; DINIZ, 2009, p. 95). O trabalho que segue está, portanto, a se sustentar na representação legal da entidade em relação ao empresariado industrial local, à sua natureza corporativista. Parte-se de sua ação política, definida como representativa do empresariado, a fim de se verificar a forma dessa ação e os valores nela contidos. Não obstante, faz-se necessário examinar a abrangência dessa representação, o que deverá ser respondido pelo apoio às suas ações.

A metodologia empregada tem como centro a análise qualitativa de três formas de ação divulgadas pela entidade representativa dos industriários paranaenses: a (i) Rede de Participação Política; o (ii) Movimento A Sombra do Imposto; e (iii) a revista Observatório da Indústria. Essas três iniciativas operam por meio de revistas e cartilhas para divulgação, um abaixo-assinado e integração com outras entidades. Por este caminho, busca-se apresentar essa entidade sindical como um grupo visando interferir na agenda e criar um ambiente favorável aos seus valores, e interesses, perante demais grupos e cidadãos, destacando que não se objetiva mensurar a influência da entidade pelo exame do sucesso 
ou fracasso dos Projetos de Lei que apoia ou diverge, como fez Mancuso para o caso da CNI (MANCUSO, 2007).

Antes de adentrar a fundamentação e revisão da literatura, um último ponto deve ser tratado. Refere-se à escolha pela ação em relação ao Legislativo, uma vez que poderia ser questionada caso se afirmasse a baixa eficiência dessa instituição. Sobre isso, destaca-se o seminal trabalho de Fernando Limongi, que apresentou uma percepção do "presidencialismo de coalizão" em que contraria o clássico conceito cunhado por Sérgio Abranches. Isso pois, Abranches apresentava esse presidencialismo como uma característica do sistema brasileiro que torna-o pouco eficiente, pois de difícil formação de coligações partidárias (LIMONGI, 2006, pp.19-20). Limongi, entretanto, não compartilha da visão pessimista de Abranches, defendendo que esse sistema " [...] do ponto de vista da sua estrutura, da forma como efetivamente funciona, há pouco que permita distinguir o sistema político brasileiro de outras democracias ditas avançadas ou consolidadas." (LIMONGI, 2006, p.19). O próprio “poder de agenda" legado ao Executivo permitiria essa semelhança com as democracias indicadas. Entretanto, para que possa impor sua agenda, o Executivo não pode fazê-lo contra a vontade da maioria parlamentar (LIMONGI, 2006, p. 33). Haveria, portanto, barganha e, assim, um Legislativo significativo (LIMONGI, 2006, p.35). A importância do Legislativo como alvo da ação empresarial é, entretanto, amplamente considerada para a redemocratização (DINIZ, 1997; MANCUSO, 2007; TOMIO \& RICCI, 2012).

\section{FUNDAMENTAÇÃO TEÓRICA E REVISÃO DA LITERATURA}

Para iniciar essa discussão, cabem algumas definições. Primeiramente, uma vez que a definição de grupo de interesses remete a um grupo que não exerce necessariamente pressão, parte-se dessa noção. Os grupos de interesse podem ser definidos de acordo com interesses compartilhados, comuns, tornando-se “[...] grupo de pressão se tenta obter dos poderes públicos matéria que regulamente a entrada de novos elementos nesse sector." (MEYNAUD, 1966, p.13) Tal definição também sustenta-se em Truman, que delimita com maior precisão esses grupos, afirmando que no momento em que fazem suas reivindicações sobre instituições de governo, acabam por se tornar grupos de interesse politico. ${ }^{5}$ (TRUMAN,

\footnotetext{
5 " [...] an interest group is a shared-attitude group that makes certain claims through or upon other groups in the society. If and when it makes its claims through or upon any of the institutions of government, it becomes a political interest group." (TRUMAN, 1951, pp. 11-44)
} 
1951, p.37) Acredita-se, e esta é a hipótese deste trabalho, que a ação política que apresenta-se em seguida tem efeito de pressão, o que também permitirá a definição do grupo como de pressão. Para Truman, é o próprio método de ação, caracterizado pela pressão, objetivando fazer valer suas preferências, que caracteriza um grupo de interesse político como grupo de pressão. ${ }^{6}$ (TRUMAN, 1951, p.39) Os grupos de pressão seriam parte enquanto fase seguinte dos grupos de interesse. Nesse aspecto, busca-se apresentar a confirmação dessa hipótese examinando-se, para isso, as formas como a entidade patronal tenta transpor seus valores e preferências para além do grupo restrito, transbordando a qualidade de grupo de interesse para grupo de interesse político e/ou de pressão.

\subsection{DIFICULDADES DA AÇÃO COLETIVA E O CORPORATIVISMO}

Por outro lado, há a problematização do tema realizada por Olson, considerando a possibilidade de que os grandes grupos, com integrantes diversos, apresentam dificuldades para organização de uma ação coletiva, uma vez que seus membros tendem a não assumir os custos dessa ação se ela propõe benefícios difusos. Essa questão aponta a necessidade de incentivo para que, nesses casos, os membros desses grupos organizem-se para uma ação coletiva. Portanto, a maior dificuldade para a organização em torno de um objetivo, para um grupo latente, seria, expõe o autor, a multiplicidade de interesses presentes numa mesma organização. O autor explica que: "Ele [o grupo latente] se distingue pelo fato de que, se um membro ajudar ou não ajudar a prover o benefício coletivo, nenhum outro membro será significantemente afetado e, portanto, nenhum terá razão para reagir.” (OLSON, 2011, pp. 56-57) Olson também destaca que o interesse imediato de um grupo pode ir em franco desacordo com o de outro, muitas vezes concorrentes, ainda que membros de uma mesma organização. A necessidade de uma coação externa se dá exatamente porque essa competição poder eliminar os grupos concorrentes. (OLSON, 2011, p.22) Como, contudo, os membros individuais tendem a não dispender recursos para aquilo que beneficiará a todos - principalmente se os resultados forem atingidos sem sua atuação -, a ação coletiva tem grandes impedimentos. Assim, sua existência, de uma ação coletiva, dar-se-ia, conclui Olson, como subproduto de "algum outro propósito" a que esses grupos se unem. (OLSON, 2011, p.148)

\footnotetext{
6 "If the word 'pressure' has more than a simply figurative meaning, it suggests a method or a category of methods that may be used by an interest group to achieve its objectives. Even if the methods implied can be described precisely, unless we can demonstrate that all political interest groups use them, the term 'pressure group' will indicate merely a stage or phase of group activity and will not serve as a satisfactory equivalent for 'interest group' or 'political interest group', as these have been defined." (TRUMAN, 1951, p.39)
} 
Esse ponto é central quando se pensa a organização empresarial no Brasil. Uma vez que a diversidade dos membros de um grupo latente dificulta sua ação, tendo-se um grupo tão heterogêneo quanto o empresariado, atuando em setores diversos e, muitas vezes, com interesses competitivos, ter-se-ia sua debilidade para uma ação política organizada. ${ }^{7}$ Um texto fundamental para esta pesquisa acerca de grupos de pressão e, mais especificamente, sobre a ação e a pressão exercida pelo empresariado industrial é o de Wagner Mancuso (2007), que aborda o "lobby" da indústria no Congresso Nacional. Mancuso verifica como um tema específico, ou seja, "algum outro propósito", no caso o “custo Brasil”, foi tomado pela Confederação Nacional da Indústria (CNI) e pode unificar a ação empresarial. O sucesso obtido pela CNI nesse tema, tanto em coordenar o empresariado numa ação coletiva quanto o sucesso dessa ação em relação ao Congresso Nacional, puderam apontar para a negação da "tese da debilidade política da indústria no Brasil”. (MANCUSO, 2007, p.153)

Portanto, neste aspecto, esta pesquisa aproxima-se, ao compartilhar de conclusões do trabalho de Mancuso, que, ao analisar a agenda criada pelo setor industrial brasileiro para diminuir o “custo Brasil”, verifica

[...] evidências de que a atuação daquelas organizações empresariais [de representação do setor industrial], inclusive as organizações do sistema corporativo, se assemelha crescentemente ao lobby americano, fenômeno geralmente associado a sistemas pluralistas e considerado atípico em sistemas de corporativismo de estado, como é o caso do Brasil. (MANCUSO, 2007, p.22)

Sobre essa intrincada questão da definição e análise do lobby, torna-se necessário que se pense na questão do corporativismo e do pluralismo. Para isso, busca-se em Paulo Trigo Pereira, sua apresentação de duas "situações limites", como tipos "puros" de organização de interesses:

Numa, os interesses são organizados de forma a dependerem funcional e organicamente do poder político (corporativismo de Estado). Noutra o Estado é apenas um veículo de transmissão e de mediação dos interesses organizados que competem entre si (pluralismo). (PEREIRA, 2001, p.8)

No Brasil, a noção de que o corporativismo predomina tem bastante apreço em grande parte da literatura. A percepção de um Estado que impede o surgimento de grupos

\footnotetext{
7 Sobre a fragilidade do empresariado brasileiro apontamos os seguintes trabalhos: MARTINS, L. Estado capitalista e burocracia no Brasil pós-64. $2^{\text {a }}$ ed. Rio de Janeiro: Paz e Terra, 1985. Também: BOSCHI, R. Elites industriais e democracia: hegemonia burguesa e mudança política no Brasil. Trad.: Patrick Burglin. Rio de Janeiro: Graal, 1979.
} 
de interesse, mantendo o monopólio da representação, tornou-se clássica, estando presente em autores como Simon Schwartzman (2007) ou mesmo Maria do Carmo Campello de Souza (1976).

Schwartzman argumenta que a relação entre Estado e sociedade civil no Brasil se originou numa construção histórica em que o Estado constitui-se como ator principal, passando a agir com autoritarismo e impedindo que a representação e conflito de classes, assim como um próprio desenvolvimento de classes que pudessem tomar consciência de si, ocorresse (SCHWARTZMAN, 2007, p.47). Campello de Souza, por sua vez, destaca a fragilidade dos partidos no Brasil, incapazes de representarem os grupos de interesse, dado a "[...] existência prévia de uma organização estatal forte [que] tem efeitos consideráveis sobre o desenvolvimento e a posterior configuração do sistema partidário.” (CAMPELLO DE SOUZA, 1976, p.31)

Outro trabalho fundamental, em que, considerando o corporativismo de Estado formado no Brasil, foi desenvolvida a "tese da debilidade política da indústria no Brasil", é o de Eli Diniz, em que a autora apontava para o forte corporativismo estabelecido desde 30 como formulador de um Estado hipertrofiado. Diniz afirmava que, nos anos de 1980, dada a crise do "estatismo-desenvolvimentismo", houvera, um momento propício para se verificar a capacidade de organização da elite empresarial para coordenar a pressão por um novo modelo (DINIZ, 1997, pp. 12-13). A autora chega a afirmar a existência de alguns momentos de pressão organizada, sustentando que, por exemplo, as "elites industriais e comerciais" teriam exercido pressão contra o estatismo nos anos 70. Porém, explicita que "[...] apesar de terem desempenhado um papel importante na rejeição do intervencionismo estatal, os empresários revelaram-se incapazes de exercer a liderança do processo de mudança em direção a uma nova concepção de desenvolvimento.” (DINIZ, 1997, p. 13) Sem projeto, essa elite seria, muitas vezes, favorável a diminuição do Estado num sentido de regulador, entretanto, ao mesmo tempo, buscaria proteção estatal para setores em dificuldade. Dessa incapacidade de unificar interesses numa pauta comum, resultaria a incapacidade de articulação política, o que sustenta a tese da debilidade política. Portanto, poder-se-ia, defende Diniz, verificar "[...] o descompasso entre a adesão ideológica [dos empresários] ao neoliberalismo e um padrão de comportamento pautado pela prevalência de práticas corporativas.” (DINIZ, 1997, p.13)

Diniz também apresenta uma explicação histórica para o corporativismo no Brasil e, nesse caso, a debilidade da indústria, criticando explicações que defendem a orientação populista das elites latino-americanas. Defende, deste modo, que "[...] os problemas 
enfrentados podem ser examinados em sua conexão com os processos históricos vinculados à constituição do Estado, à estruturação dos mecanismos de articulação entre instância de poder e a sociedade e às formas de incorporação de atores estratégicos ao sistema político.” (DINIZ, 1997, p. 17)

Assim, considerando essa literatura, poder-se-ia afirmar que a produção no Brasil esteve, pelo menos desde 1930, atada ao Estado e consentindo em renunciar de atuar politicamente, caracterizando-se como um setor débil. Destaca-se que o problema da fragilidade ou força do empresariado industrial é central quanto à sua ação. Nesse mesmo sentido da defesa do argumento da debilidade política do empresariado industrial, contudo não tomando o corporativismo e o "lobby" como elementos necessariamente contraditórios, o que também não o faz Mancuso, Álvaro Bianchi (2001) traça um histórico da representação empresarial no Brasil.

O início da representação industrial, aponta Bianchi, constituiu-se entre 1945 e 1954, marcado pela ascensão da indústria como setor "mais dinâmico da economia brasileira”. (BIANCHI, 2001, p.124) De 1964 até o final da ditadura militar ter-se-ia dado o apoio dos empresários ao regime, ainda que também a diminuição da representação pelo empresariado em relação ao período anterior. Por outro lado, parte do empresariado seria chamado para dentro do Estado, atuando diretamente na elaboração das políticas industriais. (BIANCHI, 2001, p.125-6) Nesse período também deu-se, segundo Bianchi, uma oposição à centralização efetuada pelos tecnocratas, ainda que não oposição ao regime. Portanto, uma conversão a um projeto liberalizante e uma maior afinidade com as regras democráticas, opondo-se ao regime. (BIANCHI, 2001, p.126-7) A partir dos anos de 1980, entretanto, iniciar-se-ia um processo de crise da representação empresarial e, consequentemente, uma fragilidade de sua atuação política. Esse processo teve como "[...] sinal mais evidente [...] a multiplicação de entidades empresariais e as crises internas permanentes ocorridas no interior das antigas federações e confederações." (BIANCHI, 2001, p.129) Assim, aponta o autor, os interesses patronais passaram a estar dispersos, dificultando uma ação coletiva, o que acaba por corroborar a "tese da debilidade política da indústria no Brasil". Essa noção do fim do protecionismo estatal nesses anos 80 e 90 é corroborada por Maria Antonieta Leopoldi, que afirma que: "As agências governamentais responsáveis pelas políticas de tarifa e câmbio, que protegeram a indústria e consolidaram o mercado nacional [...] foram progressivamente desmanteladas e esvaziadas na Nova República, em especial no governo Collor.” (LEOPOLDI, 2000, p.20) 


\section{2. "LOBBY" E CORPORATIVISMO NO BRASIL}

A pesquisa de Mancuso, enfocando o comportamento do empresariado brasileiro apresentou resultados diferentes dos propostos pela "tese da debilidade política da indústria no Brasil". Mancuso aponta para a existência de grupos de interesse e lobby no Brasil, ainda que em um sistema de corporativismo de Estado. (MANCUSO, 2007, p.22) Mancuso verifica como a CNI foi capaz de atrair para si a representação do empresariado em torno do tema do "custo Brasil" e exercer pressão para sua redução. A manutenção do sistema corporativista, como se sabe, não foi eliminada, ainda que, como afirma Leopoldi, nas últimas décadas do século XX tenha surgido uma "[...] pluralidade de novas associações empresariais, mas elas ainda resistem a se desligar da tutela governamental". (LEOPOLDI, 2000, p.21) Desse modo, o antagonismo entre corporativismo e pluralismo no Brasil apresenta-se como um modelo inconsistente, não servindo para explicar a ação empresarial.

Também Eli Diniz defende, nesse momento, a capacidade de mobilização e o do empresariado brasileiro, capaz de agir coletivamente, pactuando com o Estado em diversos momentos da história política nacional. (DINIZ, 2010, p.102) Assim, Mancuso expõe conclusões divergentes em relação à debilidade da representação política da indústria no Brasil daquela primeira literatura, de Schwartzman, Campello de Souza e da primeira Diniz aqui tratada. Esta apresentação, entretanto, não objetiva concluir esse debate, ainda que a hipótese a ser testada pensa na força do empresariado em se organizar e exercer pressão. Contudo, aqui não se analisou os sucessos e/ou insucessos da representação industrial, uma vez que o foco da pesquisa é, sobretudo, a ação política desse grupo.

Mancuso verificou que o "custo Brasil" passou a "[...] designar fatores que prejudicam a competitividade das empresas do país diante de empresas situadas em outros países." (MANCUSO, 2007, p.27) Apresenta, então, o “custo Brasil”" como elemento de agregação e unidade da representação empresarial, que teria passado a adotar uma ação coletiva, apesar da quantidade de atores envolvidos. O que teria tornado o "custo Brasil" elemento de preocupação de toda a indústria foi a compreensão da necessidade de adaptação a uma concorrência maior, proveniente da tendência liberal assumida na economia. (MANCUSO, 2007, p.29) Entretanto, essa necessidade não pode ser entendida como causa suficiente da ação coletiva da indústria. O que uniu os empresários em torno dessa pauta foi a capacidade de organização da CNI, que liderou outras associações industriais sensíveis ao tema (MANCUSO, 2007, p.52). 
Em vista desse debate, e objetivando verificar a hipótese aqui lançada, isto é, de que a FIEP configurou-se como grupo de pressão, tornando-se capaz de assumir os custos de uma ação coletiva, tal como foi a CNI apresentada por Mancuso, parte-se para a apresentação de três formas de ação, visando verificar sua qualidade, os valores e preferências desse sindicato. Registra-se ainda em tempo que o recorte temporal realizado é o da presidência de Rodrigo da Rocha Loures, portanto, já nos anos 2000.

\section{FORMAS DE AÇÃO, VALORES E PREFERÊNCIAS DA FIEP}

As três formas de ação política destacadas nesta pesquisa caracterizam-se pela intenção de mobilizar a sociedade, objetivando o incremento da sua participação democrática e defesa de um desenvolvimento econômico "sustentável". Pode-se verificar, portanto, a defesa realizada pela entidade patronal de um modelo político pluralista em que as forças produtivas estivessem na vanguarda dessa mobilização da sociedade, controlando ou fiscalizando o Estado e os agentes políticos e burocráticos.

A identificação desse projeto é, primeiramente, constatada ao considerar-se a "Rede de Participação Política", iniciativa da FIEP nascida em 2006, que buscou tratar de temas tidos como relevantes para o "interesse coletivo", não somente do "empresariado", mas da "sociedade". A Rede é apresentada pela entidade como:

[...] uma iniciativa apartidária criada para estimular o empresariado e toda a sociedade a participarem continuamente da política. Trata-se de um espaço democrático para a discussão e proposição de mudanças na relação entre a sociedade e o Estado. Buscando a democracia e o crescimento e desenvolvimento sustentável do País, a Rede de Participação Política propõe-se a contribuir para o atendimento aos anseios e causas de interesse coletivo. (Federação das Indústrias do Estado do Paraná (FIEP), Rede de Participação Política)

Deste modo, verifica-se que a Rede não se limita a defender os interesses imediatos do empresariado industrial paranaense, mas, além disso, procura defender uma concepção de política e, desse modo, os valores que pautam sua ação. Num trabalho publicado no ano de 2012, Paulo Roberto Costa e Andressa Silvério França, analisam a Rede pela sua natureza e modo de agir por meio de "[...] um conjunto de ações concretas com continuidade no tempo e com objetivos gerais a serem alcançados." (COSTA; FRANÇA, 2012, p.181) Esses valores, e aqui está presente sua concepção de democracia, visam situar a entidade como um grupo de interesses políticos, portanto, defendendo uma 
democracia plural que alavancaria o "[...] crescimento e desenvolvimento sustentável do país."

Costa e França apresentam os meios de ação da Rede do seguinte modo:

[...] (a) um curso de formação política à distância, intitulado Democracia, Redes Sociais e Sustentabilidade, que utiliza o livro-texto Alfabetização Democrática O que Podemos Pensar (e Ler) para Mudar nossa Condição de Analfabetos Democráticos e que usa um software que permite que o curso seja feito pela internet, com o acompanhamento do aluno on-line; (b) a iniciativa 'Vigilantes da Democracia', que, através do Sistema de Monitoramento e Avaliação dos Eleitos, acompanha as atividades políticas e o comportamento do Governador do Estado, dos 54 deputados estaduais, dos 30 deputados federais e dos três senadores eleitos pelo Paraná, permitindo que tanto os eleitores quanto os próprios políticos possam fazer comentários sobre as informações levantadas na imprensa; (c) a plataforma Ning e o Twitter, que pretendem ser '[...] um espaço destinado à discussão e (à) proposição de mudanças democratizantes na relação entre a sociedade e o Estado'. A plataforma Ning tem sido usada principalmente para as atividades das Redes de desenvolvimento Local (RDL); (d) o Projeto Político de desenvolvimento das Cidades do Paraná, o qual se desdobrou em outros dois, o projeto Cidades Inovadoras, voltado para o desenvolvimento de formas de gestão e governança das cidades e para o aumento do controle da sociedade sobre o Estado e o governo; e as Redes de Desenvolvimento Local, que são ações desenvolvidas nos bairros, com uma metodologia bem estabelecida e apresentada de forma didática em sua página eletrônica, envolvendo mais de 50 localidades em Curitiba e no interior do Estado (COSTA; FRANÇA, 2012, p.186).

Além disso, a Rede distingue-se pela inovação e capacidade de organizar-se com outras entidades. Nesse aspecto, uma de suas principais características, que molda seu padrão de ação, é a proposição de ações integradas, estabelecendo relações com outras instituições, como a Universidade Federal do Paraná (UFPR), na criação e manutenção do projeto Vigilantes da Democracia. A Rede também busca outras formas de ação, por exemplo, produzindo e distribuindo cartilhas com vistas ao que chamou de "educação democrática" (COSTA; FRANÇA, 2012, p.188).

Não por acaso, a FIEP apresenta a Rede como sua "principal forma de ação política” (FIEP, Rede de Participação Política). Essa defesa de uma concepção de política e democracia é acompanhada pelo interesse aglutinador do sindicato. A FIEP chama, assim, a atenção para o que considera ser “[...] uma questão básica: o Brasil precisa voltar a crescer. Mas o desenvolvimento econômico e social só vai ocorrer quando houver instituições políticas sérias, modernas e ágeis.” (FIEP, Rede de Participação Política) Assim, por meio da Rede, visa defender os interesses empresariais, tentando colocar o empresariado organizado sob sua liderança no centro das decisões políticas, pelo menos enquanto grupo de pressão, buscando influenciar a formação da agenda pública. Portanto, concebendo a necessidade de ação coletiva do empresariado, a FIEP chama a 
responsabilidade para si, considerando-se capaz de assumir esse custo - e dispender recursos no encalço desse objetivo.

Nesse mesmo espírito de ação e pressão, o Movimento A Sombra do Imposto, outra iniciativa da Federação, realiza: "Com uma cartilha simples e didática, [...] uma mobilização para mostrar à população que os impostos são elevados e estão presentes em cada produto que compramos ou serviço que contratamos." (FIEP, Movimento A Sombra do Imposto) O Movimento tem caráter mais atuante, uma vez que produziu um abaixoassinado, nomeado de Movimento Simplifica Já, a fim de promover uma "Proposta de Emenda à Constituição, que pede a simplificação das normas tributárias do país, [e que] chegue até o Congresso Nacional e seja analisada por nossos representantes." (FIEP, Movimento A Sombra do Imposto)

O Movimento A Sombra do Imposto apresenta em seu sítio na internet dados referentes à carga tributária por produtos, além de informações sobre o sistema de cobrança de impostos. Com isso, afirma haver uma cobrança excessiva de impostos no Brasil. Por outro lado, afirma haver uma qualidade baixa de serviços públicos de saúde, educação e segurança, o que é creditado, sobretudo, à corrupção, assim como à baixa qualidade da administração pública. O combate à corrupção e a melhoria da administração pública são, na sua concepção, além do principal, o combate à alta carga tributária, os dois eixos a serem girados pela sociedade.

Do mesmo modo que a Rede, o Movimento A Sombra do Imposto procura mobilizar o empresariado em torno de uma causa, colocando, para isso, a FIEP no centro da ação. Objetiva com isso, além de defender valores políticos específicos, agir enquanto grupo de interesse que identifica e valoriza uma relação plural com o Estado, visando interferir na agenda e criar um ambiente favorável aos seus interesses perante demais grupos e cidadãos, pressionando o governo para as suas demandas.

Por fim, a entidade realiza e divulga um periódico trimestral, destinado aos profissionais e empresários do setor, desde 2004, chamado Observatório da Indústria. Dedicado a temas relacionados "[...] à economia regional e ao universo industrial - o que abrange comércio exterior, infraestrutura, tecnologia, inovação, empreendedorismo, gestão, responsabilidade social e meio ambiente, entre outros.” (Observatório da Indústria, FIEP) Concomitantemente à inovação industrial e ao contexto econômico, o periódico visa divulgar serviços da entidade para seus associados, apresentando-se e reforçando sua identidade de entidade representativa do setor. 
A seguir, apresenta-se tabela em que se destaca a proposta de cada uma das ações analisadas, a forma dessa ação e o objetivo pretendido.

TABELA 1 - FORMAS DE AÇÃO POLÍTICA

\begin{tabular}{l|l|l|l}
\hline & \multicolumn{1}{|c|}{ Rede } & \multicolumn{1}{c}{ Movimento } & \multicolumn{1}{c}{ Revista } \\
\hline Proposta & $\begin{array}{l}\text { Ser instrumento para a } \\
\text { participação política da } \\
\text { sociedade }\end{array}$ & $\begin{array}{l}\text { Mobilizar a } \\
\text { sociedade contra a } \\
\text { "alta carga } \\
\text { tributária" e contra } \\
\text { Ação }\end{array}$ & $\begin{array}{l}\text { Divulgar serviços da } \\
\text { entidade, inovações } \\
\text { do setor industrial e } \\
\text { informações de } \\
\text { conjuntura econômica }\end{array}$ \\
& $\begin{array}{l}\text { Curso de formação política para } \\
\text { lideranças empresariais; } \\
\text { acompanhamento das atividades } \\
\text { políticas; mobilização da } \\
\text { sociedade por meio de redes } \\
\text { sociais; projetos de } \\
\text { desenvolvimento local }\end{array}$ & $\begin{array}{l}\text { Cartilha para a } \\
\text { sociedade; abaixo- } \\
\text { assinado; palestras }\end{array}$ & $\begin{array}{l}\text { Periódico para } \\
\text { associados }\end{array}$ \\
\hline Objetivo & $\begin{array}{l}\text { Defender concepções/valores } \\
\text { acerca da política e economia } \\
\text { diretamente em relação à }\end{array}$ & $\begin{array}{l}\text { Pociedade } \\
\text { políticos para } \\
\text { demandas do setor } \\
\text { e defender essas } \\
\text { demandas em } \\
\text { relação à sociedade }\end{array}$ & $\begin{array}{l}\text { Manter unidade e } \\
\text { identidade em torno } \\
\text { da entidade } \\
\text { representativa do } \\
\text { empresariado local }\end{array}$ \\
\hline
\end{tabular}

Verifica-se, deste modo, que essas ações tiveram um caráter complementar e não isolado. Enquanto a Rede apresenta uma ação mais ampla, propositiva, de defesa aberta de valores acerca da política e da economia, o Movimento A Sombra do Imposto age para exercer pressão, mobilizando para isso a sociedade em torno dos temas da "corrupção" e da "alta carga tributária" para todos os cidadãos, e não somente para o empresariado. Por último, o periódico Observatório da Indústria aparece como elemento de aglutinação do empresariado, por meio da divulgação de serviços prestados pela entidade aos seus associados. Também vale considerar que o apoio às ações da FIEP não é restrito aos 
sindicatos patronais, mas apresenta-se de modo amplo, envolvendo várias entidades, instituições de Ensino Superior e empresas. ${ }^{8}$

\section{CONSIDERAÇÕES FINAIS}

Esta pesquisa procurou analisar a Ação Política da Federação das Indústrias do Estado do Paraná (FIEP), compreendendo-a como um grupo de interesses e pressão política. Deste modo, pode-se verificar que compartilha de certos valores e preferêncais - o que visualiza-se na qualidade de sua ação. Verificou-se como a FIEP caracterizou-se como organização capaz de mobilizar o empresariado, atraindo para si a representação dos seus interesses - assumindo os custos dessa ação coletiva. Não se apresentou índices de sucesso ou fracasso dessa elite, o que não foi objetivo deste trabalho. A preocupação do artigo esteve centrada na verificação de como a entidade representativa do empresariado industrial local pode unificar interesses e valores e transferí-los para uma ação política coletiva, tendo capacidade de assumir os custos dessa ação. Assim, as conclusões tiradas apontam para a força, e não debilidade, política da indústria, ainda que não se possa concluir categoricamente por isso - já que não se verificou o sucesso e/ou fracasso dessas ações assim como o sucesso das ações promovidas pela Rede, pelo Movimento e pela Revista.

Apresentou-se, portanto, como esse grupo foi capaz de se organizar afim de atuar para interferir na agenda e criar um ambiente favorável aos seus valores e interesses,

\footnotetext{
8 Segue relação das entidades que apoiam o Movimento A Sombra do Imposto: Associação Comercial do Paraná (ACP); Comitê de Jovens Empreendedores (CJE); Conselho Regional de Contabilidade do Paraná (CRC-PR); Conselho Regional de Engenharia e Agronomia (CREA-PR); Ordem dos Advogados do Brasil, seção do Paraná (OAB-PR); Instituto de Promoção do Desenvolvimento (IPD); Centro Internacional de Formação de Atores Locais para a América Latina (CIFAL); Conselho Regional de Economia do Paraná (CORECON); Movimento Brasil Eficiente (MBE); Sistema Fecomércio; Instituto Brasileiro de Executivos de Finanças (IBEF); Federação dos Trabalhadores da Indústria do Estado do Paraná (FETIEP); Serviço Brasileiro de Apoio às Micro e Pequenas Empresas (SEBRAE); Federação das Empresas de Transporte de Cargas do Paraná (FETRANSPAR); Federação Nacional das Empresas Contábeis e das Empresas de Assessoramento, Perícias, Informações e Pesquisas (FENACON); Federação das Associações Comerciais e Empresariais do Paraná (FACIAP); Sociedade Bíblica do Brasil; Instituto RPC; Associação Médica do Paraná (AMP); Federação dos Contabilistas do Paraná (FECOPAR); Associação dos Dirigentes de Vendas e Marketing do Brasil (ADVB-PR); Coordenadoria das Associações Comerciais, Industriais e Agrícolas do Sudeste do Paraná (CACIASPAR); Sindicato das Empresas de Serviços Contábeis e das Empresas de Assessoramento, Perícias, Informações e Pesquisas no Estado do Paraná (SESCAP-PR); Instituto Brasileiro de Qualidade e Produtividade; Clube de Seguros de Pessoas e Benefícios do Estado do Paraná (CVG-PR); Sindicato da Indústria de material de Segurança (SINDISEG); Instituto de Engenharia do Paraná; Sindicato dos Contabilistas de Curitiba e Região (SICONTIBA); Associação das Empresas da Cidade de Araucária (AECIAR); Câmara do Comércio e Indústria Brasil Japão do Paraná (CCIBJ); Confederação Nacional de Jovens Empresários (CONAJE); Sindicato das Indústrias de Fiação e Tecelagem no Estado do Paraná (SINDITêxtil); Faculdade Teológica Batista do Paraná (FTBP); Grupo UNINTER; Rede BAND; Instituto Brasileiro de Planejamento Tributário (IBPT); Rotary Club do Paraná.
} 
perante demais grupos e cidadãos, pressionando, desse modo, os decisores. A hipótese sugestionada, de que a FIEP se constitui como grupo de pressão, e interesse político, é verificada de modo positivo por meio das formas de organização e ação da entidade. $\mathrm{O}$ exame empírico possibilitou a verificação da relação entre os valores e preferências da entidade representativa do empresariado industrial com sua ação política, ainda que não se pode concluir como prova de uma relação de causa e efeito ou mesmo do sucesso de sua pressão. Entretanto, mostrou-se como essas propriedades encontram-se articuladas, uma vez que a entidade apresentou valores e preferêncais e buscou constranger a sociedade e o Estado à sua realização.

Esta pesquisa também tratou do problema do corporativismo, tema saliente na literatura sobre o empresariado no Brasil. Concluíu-se pela possível relação entre o corporativismo das associações representativas e, por outro lado, uma ação características de sociedades com sistemas políticos pluralistas, em que o "lobby" é atividade comum. Pode-se perceber que, apesar da relação entre Estado e entidades representativas empresariais, ou pelo menos em grande parte delas, incluindo a FIEP, essas, ou pelo menos a Federação do Paraná, pode organizar-se como grupo de interesse político e pressão.

Quanto as três formas de ação da entidade analisada, apresentaram um caráter de complementaridade na sua ação política. Viu-se a Rede de Participação Política como uma forma de ação abrangente e inovadora, visando, com uma ação proativa, estimular a sociedade à defesa de valores compartilhados pela entidade. A Rede apresentou-se como a mais complexa das três formas de ação, uma vez que atua de diversas maneiras e, mesmo, em relação com outras instituições, como a Universidade Federal do Paraná. O Movimento A Sombra do Imposto também caracteriza-se pela relação com a sociedade, entretanto, sua atuação se dá, sobretudo contra a carga tributária e à "corrupção". Esse movimento atua de maneira mais concreta, utilizando-se de cartilhas de propaganda, abaixo-assinado e palestras. A revista Observatório da Indústria apresenta-se como elemento para aderência de peças em torno da entidade. Visa, portanto, a coesão do empresariado em torno da elite empresarial. Para isso, caracteriza-se como meio de divulgação de serviços da entidade para seus associados.

Assim, essas três formas de ação puderam indicar as formas com que o empresariado pensa a política, sua concepção e defesa da democracia e seu direcionamento para promover ações coletivas. O material produzido e os modos de ação examinados indicaram as preferências da Federação da Indústria do Paraná. Pode-se perceber, portanto, esse grupo numa perspectiva pluralista, atuando de modo propositivo com a sociedade e 
deste modo defendendo seus valores, além de exercendo pressão direta sobre o Estado na intenção de realizar suas preferências.

\section{REFERÊNCIAS BIBLIOGRÁFICAS}

ALMOND, G. A.; VERBA, S. The Civic Culture: political attitudes and Democracy in Five Nations. Newbury Park-CA, Sage publications, 1989.

BIANCHI, Á. Crise e representação empresarial: o surgimento do Pensamento Nacional de Bases Empresariais. Revista de Sociologia e Politica, Curitiba, 2001. nº 16, p. 123-142.

BRESSER-PEREIRA, L. C.; DINIZ, E. Empresariado industrial, democracia e poder político. Novos Estudos Cebrap, São Paulo, no 84, 2009, p. 83-99.

COSTA, P. R. N.; ENGLER, Í. G. F. Elite empresarial: recrutamento e valores políticos (Paraná, 1995-2005). Opinião Pública, Campinas, 2008. v. 14, nº 2, p. 486-514.

COSTA, P. R. N.; FRANÇA, A. S. T. Da Responsabilidade Social à Responsabilidade Política: A Rede de Participação Política. In: DALLA COSTA, Armando et. al. Desenvolvimento e crise na América Latina. Curitiba: CRV, 2012, pp. 179-200.

DAHL, R. A. Who Governs? Democracy and Power in an American City. New Haven and London, Yale University Press, 1989.

DINIZ, Eli. Corporativismo em transição. In: Crise, Reforma do Estado e Governabilidade: Brasil 1985-95. Rio de Janeiro: Editora Fundação Getúlio Vargas, 1997. pp. 11-39.

DINIZ, E. M. Empresariado industrial, representação de interesses e ação política: trajetória histórica e novas configurações. Politica e Sociedade, Florianópolis, 2010. v. 9, n 17 , p. 101-139.

EASTON, D. Teoria e pesquisa de comportamento. In: Uma teoria da análise política. Rio de Janeiro: Zahar Editores, pp. 19-46, 1968.

FEDERAÇÃO DAS INDÚSTRIAS DO ESTADO DO PARANÁ (FIEP). Movimento A Sombra do Imposto. Acesso em 11/12/2013. Disponível em: $<$ http://www.fiepr.org.br/acoesinstitucionais/FreeComponent20774content172524.shtml.>

FEDERAÇÃO DAS INDÚSTRIAS DO ESTADO DO PARANÁ (FIEP). Rede de Participação Política. Acesso em 11/12/2013. Disponível em: <http://www.fiepr.org.br/acoesinstitucionais/FreeComponent20774content170386.shtml.>

LEOPOLDI, M. A. P. Introdução. In: Política e Interesses na Industrialização Brasileira: as associações industriais, a política econômica e o Estado. São Paulo, Paz e Terra, 2000, pp. 19-32. 
LIMONGI, F. A democracia no Brasil - Presidencialismo, coalizão partidária e processo decisório. Novos Estudos - CEBRAP, nº 76, 2006, pp. 17-41.

MAYNAUD, J. Os grupos de pressão. Trad.: Pedro Lopes de Azevedo. Lisboa: EuropaAmérica, 1966.

MANCUSO, W. P. O lobby da indústria no Congresso Nacional: empresariado e política no Brasil contemporâneo. São Paulo: Edusp, 2007.

OBSERVATÓRIO DA INDÚSTRIA. (2004-2012) Curitiba, FIEP.

OLSON, M. A lógica da ação coletiva: os benefícios públicos e uma teoria dos grupos sociais. Trad.: Fabio Fernandez. São Paulo: EdUSP, 2011.

PEREIRA, P. T. Governabilidade, grupos de pressão e o papel do Estado. Apresentado no I Encontro Nacional de Ciência Política, Fundação Calouste Gulbenkian, 1999. Disponível em:

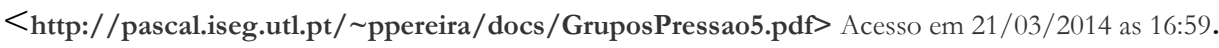

SCHWARTZMAN, S. As bases do autoritarismo brasileiro. 4ªed. Rio de Janeiro: Publit Soluções Editoriais, 2007.

SOUZA, M. C. C. de. Estado e partidos políticos no Brasil (1930 a 1964). São Paulo: AlfaÔmega, 1976.

TOMIO, F. R. L; RICCI, P. O Governo Estadual na Experiência Política Brasileira: os desempenhos legislativos das Assembléias Estaduais. Revista de Sociologia e Política, v. 21, $\mathrm{n}^{\circ}$ 41, p. 193-217, fev. 2012.

TRUMAN, D. B. Groups and Society. In: . Governmental Process: Political Interests and Public Opinion. New York: Alfred A. Knopf, 1951, pp. 11-44. 